\title{
Iron Overload
}

\author{
Emanuele Angelucci
}

\subsection{Introduction}

Iron overload/toxicity is an unavoidable consequence in several diseases characterized by anemia and red blood cell transfusion requirement.

Our knowledge of iron pathophysiology has much improved during the last two decades, and we now recognize that iron damage is related not only to iron level "per se" but to the presence in the serum of non-transferrin forms of iron (nontransferrin bound iron $=\mathrm{NTBI}$ ). A component of NTBI, called labile plasma iron (LPI), is a potent redox-active agent capable of permeating into cells in an uncontrolled way, thus inducing cellular iron overload and impacts the delicate equilibrium of labile cellular iron (LCI). The breakage of LCI balance catalyzes the formation of reactive oxygen species (ROS), which leads to cytotoxic cell injury (DNA damage, lipid peroxidation, protein modification, and mitochondrial damage). Iron toxicity depends on many factors in addition to the iron level: the quantity of the abovementioned toxic iron-related species, duration of exposure, individual's antioxidant genetics, and environmental factors (Coates 2014). Notably NTBI and LPI appear in the serum only when transferrin saturation exceeds 60-70\% (de Swart et al. 2016) and are cheatable forms of iron.

\footnotetext{
E. Angelucci $(\bowtie)$

Department of Oncology and Hematology, IRCCS Ospedale Policlinico San Martino, Genova, Italy e-mail: emnang@tin.it
}

NTBI and LPI are direct markers of ongoing cellular iron accumulation and tissue damage. Their measurement is today available in selected laboratories for research purposes only. A standardization program is ongoing (de Swart et al. 2016), and hopefully NTBI and LPI assays will be available in the next future for clinical use. Transferrin saturation is at the moment a valid surrogate indicating, when exceeding 60-70\%, presence of NTBI /LPI in patient serum.

Here will be discussed the impact of iron toxicity on HSCT outcome and therapeutic options (Angelucci and Pilo 2016). This chapter will be divided in three sections with the following meanings:

- Before transplant: any time before the starting of the conditioning regimen

- During transplant: from the start of conditioning regimen up to a sustained engraftment is achieved

- After transplant: after sustained engraftment has been achieved

\subsection{Iron Overload Before HSCT (Before the Start of Conditioning)}

In thalassemia it has been very well demonstrated that HSCT outcome is significantly impacted by a story of irregular chelation, presence of liver fibrosis, and hepatomegaly (Angelucci 2010). 
Now we can recognize that all the three risk factors are related to intensity and duration of tissue exposition to the abovementioned iron toxicrelated species (Angelucci et al. 2017).

Therefore, any effort should be made to regularly suppress NTBI/LPI in the years before transplant to prevent tissue damage. This target can be achieved with early, regular, and consistent iron chelation. Thus, in any patient receiving transfusion therapy who may have an HSCT in the future, the decision starting chelation is critical and should be undertaken as soon as possible. Moreover, chelation must regular long life.

Limited data are available on the rationale for intensive pre-HSCT chelation therapy unless sufficient time is available to correct iron overload and warrant tissue lesions repair.

\subsection{Iron Overload During HSCT (From the Start of Conditioning Up to Sustained Engraftment)}

During conditioning regimen, a huge amount of NTBI and LPI enter the circulation due to massive erythroid marrow lysis (Dürken et al. 1997). Moreover, until the erythroid recovery begins, no iron can be released by transferrin to the erythroid system. Once erythroid recovery initiates transferrin-iron is greedily captured by the erythroid system and unbound transferrin able to receive iron from reticular endothelial system and, to a mush less extent, from storages appears in the serum. Non-transferrin-iron is uptaken by erythroid cells but is not utilized for hemoglobin synthesis (Prus and Fibach 2011).

Recent transplant animal studies demonstrated that iron toxicity could impair the hematopoietic niche by damaging hematopoietic stem cells' self-renewal potential, proliferation, differentiation, and the marrow microenvironment (Pilo and Angelucci 2018). These data suggest that iron can impact the HSC engraftment, the hemopoietic recovery, and possibly transplant outcome. From a clinical point of view, limited evidence is available. Visani and colleagues demonstrated, in an uncontrolled study, that in cases of poor and delayed engraftment, iron chelation can help in stabilizing hemopoietic engraftment (Visani et al. 2014).

Inclusion of chelation therapy during the transplant phase to suppress NTBI/LPI should be considered an experimental treatment; however, in case of slow, delayed, or incomplete marrow recovery and high transferrin saturation, chelation should be considered.

\subsection{Iron Overload After HSCT (After Sustained Engraftment Has Been Achieved)}

After successful transplantation, patients are usually free from transfusion support but affected by the already acquired iron overload that cannot be eliminated without active intervention. In this condition the already acquired intracellular iron overload continues to disrupt the delicate LCI equilibrium and promotes ROS generation. It has been prospectively demonstrated in transplanted thalassemia patients that elevated transferrin saturation persists indefinitely without treatment and liver disease progresses even in the absence of other comorbidities (Angelucci et al. 2002). Of course the deleterious effect can be worsened by presence of comorbidities even with low level of iron accumulation (Angelucci et al. 2002).

Therefore, even because of the results of epidemiologic studies in thalassemia (Coates et al. 2016; Puliyel et al. 2015) and in the normal population (Ellervik et al. 2011) in the post transplant setting, the target iron level should be a normal iron level. Normal transferrin saturation excluding the presence of toxic iron-reactive species should be the target level of post transplant iron removal.

Because of the acquired effective erythropoiesis, phlebotomy (Angelucci et al. 1997; Inati et al. 2017) can be an alternative to chelation. Table 46.1 reports the pros and cons for selecting phlebotomy or iron chelation for post-HSCT iron removal. 
Table 46.1 Factors to be considered in selecting the appropriate post-HSCT iron removal strategy

\begin{tabular}{|c|c|c|}
\hline & Phlebotomy & Chelation \\
\hline Pros & $\begin{array}{l}\text { - Efficient } \\
\text { - Safe } \\
\text { - Inexpensive } \\
\text { - Permits complete iron } \\
\text { removal and } \\
\text { normalizes iron body } \\
\text { content }\end{array}$ & 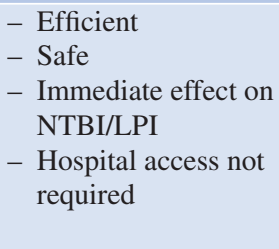 \\
\hline Cons & $\begin{array}{l}\text { - Requires sustained } \\
\text { engraftment (not } \\
\text { usable in the early } \\
\text { post-HSCT period) } \\
\text { - Immediate effect on } \\
\text { NTBI/LPI still } \\
\text { remains to be verified } \\
\text { - Hospital access } \\
\text { required }\end{array}$ & $\begin{array}{l}\text { - Expensive } \\
\text { - Warning of renal } \\
\text { toxicity in the case } \\
\text { of concomitant use } \\
\text { of CSA } \\
\text { - Possible increase in } \\
\text { toxicity for low } \\
\text { level of iron burden }\end{array}$ \\
\hline
\end{tabular}

\section{Key Points}

- Iron toxicity depends on the presence of free iron species: non-transferrin bound iron (NTBI) and labile plasma iron (LPI).

- Prevention of tissue damage by regularly and consistently suppressing tissue reactive iron species in the years before HSCT is the key factor to improve transplant outcome.

- Iron toxicity can impair the bone marrow microenvironment, the quantity and quality of bone marrow mesenchymal stem cells, the ratio of immature HSC, and the clonogenic capacity of hemopoietic stem and progenitor cells, thus impacting hemopoietic recovery and possibly transplant outcome.

- After successful HSCT, one should aim to achieve normal iron levels (i.e., normal transferrin saturation).

\section{References}

Angelucci E. Hematopoietic stem cell transplantation in thalassemia. Hematology Am Soc Hematol Educ Program. 2010;2010:456-62.
Angelucci E, Pilo F. Management of iron overload before, during, and after hematopoietic stem cell transplantation for thalassemia major. Ann N Y Acad Sci. 2016;1368:115-21.

Angelucci E, Muretto P, Lucarelli G, et al. Phlebotomy to reduce iron overload in patients cured of thalassemia by bone marrow transplantation. Italian Cooperative Group for Phlebotomy Treatment of Transplanted Thalassemia Patients. Blood. 1997;90:994-8.

Angelucci E, Muretto P, Nicolucci A, et al. Effects of iron overload and hepatitis $\mathrm{C}$ virus positivity in determining progression of liver fibrosis in thalassemia following bone marrow transplantation. Blood. 2002;100:17-21.

Angelucci E, Pilo F, Coates TD. Transplantation in thalassemia: revisiting the Pesaro risk factors 25 years later. Am J Hematol. 2017;92:411-3.

Coates TD. Physiology and pathophysiology of iron in hemoglobin-associated diseases. Free Radic Biol Med. 2014;72:23-40.

Coates TD, Carson S, Wood JC, et al. Management of iron overload in hemoglobinopathies: what is the appropriate target iron level? Ann N Y Acad Sci. 2016;1368:95-106.

de Swart L, Hendriks JCM, van der Vorm LN, et al. Second international round robin for the quantification of serum non-transferrin-bound iron and labile plasma iron in patients with iron-overload disorders. Haematologica. 2016;101:38-45.

Dürken M, Nielsen P, Knobel S, et al. Nontransferrinbound iron in serum of patients receiving bone marrow transplants. Free Radic Biol Med. 1997;22:1159-63.

Ellervik C, Tybjærg-Hansen A, Nordestgaard BG. Total mortality by transferrin saturation levels: two general population studies and a metaanalysis. Clin Chem. 2011;57:459-66.

Inati A, Kahale M, Sbeiti N, et al. One-year results from a prospective randomized trial comparing phlebotomy with deferasirox for the treatment of iron overload in pediatric patients with thalassemia major following curative stem cell transplantation. Pediatr Blood Cancer. 2017;64:188-96.

Pilo F, Angelucci E. A storm in the niche: iron, oxidative stress and haemopoiesis. Blood Rev. 2018;32:29-35.

Prus E, Fibach E. Uptake of non-transferrin iron by erythroid cells. Anemia. 2011;2011:945289. https://doi. org/10.1155/2011/945289.

Puliyel M, Mainous AG, Berdoukas V, et al. Iron toxicity and its possible association with treatment of Cancer: Lessons from hemoglobinopathies and rare, transfusion-dependent anemias. Free Radic Biol Med. 2015;79:343-51.

Visani G, Guiducci B, Giardini C, et al. Deferasirox improves hematopoiesis after allogeneic hematopoietic SCT. Bone Marrow Transplant. 2014;49:585-7. 
Open Access This chapter is licensed under the terms of the Creative Commons Attribution 4.0 International License (http://creativecommons.org/licenses/by/4.0/), which permits use, sharing, adaptation, distribution and reproduction in any medium or format, as long as you give appropriate credit to the original author(s) and the source, provide a link to the Creative Commons license and indicate if changes were made.

The images or other third party material in this chapter are included in the chapter's Creative Commons license, unless indicated otherwise in a credit line to the material. If material is not included in the chapter's Creative Commons license and your intended use is not permitted by statutory regulation or exceeds the permitted use, you will need to obtain permission directly from the copyright holder.

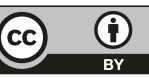

